\title{
High-sensitive cardiac troponin after CPAP in obstructive sleep apnoea: the adjusted analytical change limit (adjACL) for small variations at low concentrations
}

\begin{abstract}
To the Editor:
Copyright @The authors 2022

This version is distributed under the terms of the Creative Commons Attribution Non-Commercial Licence 4.0. For commercial reproduction rights and permissions contact permissions@ersnet.org

Received: 27 Nov 2021

Accepted: 30 Nov 2021

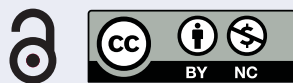

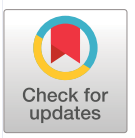

Even below the 99th percentile upper reference limit (99PURL), elevated high-sensitive cardiac troponin concentration (hs-cTn) is associated with increased cardiovascular risk [1]. However, the lower the troponin concentration, the higher the analytical imprecision [2]. It is unclear to what extent a change in hs-cTn ( $\Delta$ hs-cTn) is significant between the limit of detection (LOD) and the 99PURL. Recently, LuI et al. [3] compared, through a randomised control trial, the effect of 8 weeks of continuous positive airway pressure (CPAP) on $\Delta$ hs-cTnI in subjects with moderate-to-severe obstructive sleep apnoea (OSA) and hypertension. They showed a statistically significant variation compared to untreated subjects (adjusted mean difference $-1.74 \mathrm{ng} \cdot \mathrm{L}^{-1} ; \mathrm{p}=0.006$ ). The adjusted mean hs-cTnI decreased from 5.6 to $4.8 \mathrm{ng} \cdot \mathrm{L}^{-1}$ $(-14.3 \%)$ after CPAP, and increased from 7.9 to $8.5 \mathrm{ng} \cdot \mathrm{L}^{-1}(+7.6 \%)$ in the control group. These values are above the LOD of $1.2 \mathrm{ng} \cdot \mathrm{L}^{-1}$, but are close to the limit of quantification of $5 \mathrm{ng} \cdot \mathrm{L}^{-1}$ (hs-cTnI reagent kit 3P25, Abbott, Chicago, IL, USA). From a diagnostic standpoint, at the individual scale, the reference change value (RCV) concept assumes that the change between two serial results is significant if greater than the sum of the variations for each result. These variations are mostly analytical (analytical coefficient of variation, CVa) and biological (intra-individual, CVi) [2]. Considering two serial results, the RCV is equal to $\mathrm{Z} \times\left(\left(\mathrm{CVa}_{1}{ }^{2}+\mathrm{CVi}_{1}{ }^{2}\right)+\left(\mathrm{CVa}_{2}{ }^{2}+\mathrm{CVi}_{2}{ }^{2}\right)\right)^{1 / 2}$, with $\mathrm{Z}=1.96$ for a probability of change of $95 \%$. Considering only analytical imprecision, which mainly depends on assay methods and analysers, as the minimal unavoidable variation, and applying it to serial results, the adjusted analytical change limit (adjACL) is equal to $\pm 1.96 \times\left(\mathrm{CVa}_{1}{ }^{2}+\mathrm{CVa}_{2}{ }^{2}\right)^{1 / 2}$ [4]. To test whether the $\Delta$ hs-cTnI observed after 8 weeks of CPAP was greater than the adjACL of hs-cTnI, we used CVa for hs-cTnI concentrations ranging from 50 to $1 \mathrm{ng} \cdot \mathrm{L}^{-1}$ (mean imprecision profile), provided in the supplementary data from [2], and measured on an Architect Abbott analyser, as did Lui et al. [3]. The regression equation of the best-fit curve was $\mathrm{CVa}=3.997+(28.17 / \mathrm{hs}-\mathrm{cTnI}$ ) (figure 1). Applying this formula on serial hs-cTnI means of 5.6 and $4.8 \mathrm{ng} \cdot \mathrm{L}^{-1}$ (before and after CPAP), the adjACL was $\pm 26.2 \%$. Hence, at such low concentrations, the $\Delta$ hs-cTnI of $-14.3 \%$ is within the adjACL, meaning that the effect of CPAP is not great enough to decrease troponin more than analytical variability. According to this model, a decrease from 5.6 to at least $4.0 \mathrm{ng} \cdot \mathrm{L}^{-1}$ ( $\Delta \mathrm{hs}-\mathrm{cTnI} \leqslant-28.6 \%$, i.e. out of adjACL $\pm 28.0 \%$ ) would have been considered as significantly due to CPAP, at least in part. As expected, $\Delta \mathrm{hs}-\mathrm{cTnI}$ of the control group (7.9 to $8.5 \mathrm{ng} \cdot \mathrm{L}^{-1},+7.6 \%$ ) remains within the adjACL, calculated at $\pm 20.6 \%$. As demonstrated, the closer the concentrations are to the LOD, the greater the imprecision. This regression model reflects real analytical imprecisions for low ranges of hs-cTnI in the laboratory, with concentrations of $10 \% \mathrm{CV}$ and $20 \% \mathrm{CV}$ at 4.7 and $1.8 \mathrm{ng} \cdot \mathrm{L}^{-1}$ [5]. Another analytical consideration is lot-to-lot bias between hs-cTnI reagents and/or calibrators, which can occur over weeks and could partly bias the mean difference of $-1.74 \mathrm{ng} \cdot \mathrm{L}^{-1}$ observed by Lur et al. [3]. Illustrating this, Wu et al. [6] recently showed for Abbott hs-cTnI a lot-to-lot bias at low ranges (below $5.4 \mathrm{ng} \cdot \mathrm{L}^{-1}$ ) between -1.7 to $+2.3 \mathrm{ng} \cdot \mathrm{L}^{-1}$. A large difference of $2.5 \mathrm{ng} \cdot \mathrm{L}^{-1}$ between two successive lots was even observed (from 4.7 to $7.2 \mathrm{ng} \cdot \mathrm{L}^{-1}$ ), leading the authors to conclude that "a total analytic error $<3.5 \mathrm{ng} \cdot \mathrm{L}^{-1}$ for long-term studies with hs-cTnI concentrations $<10 \mathrm{ng} \cdot \mathrm{L}^{-1}$ could prevent erroneous reporting of results" [7]. This bias is advantageously considered in the adjACL, since it is also determined over the course of weeks.

\section{Shareable abstract (@ERSpublications)}

Interpreting change in cardiac troponin after CPAP in OSA is challenging, especially since the lower the troponin concentration, the higher the analytical imprecision. In such cases, the adjusted analytical change limit (adjACL) should be used. https://bit.ly/3eaHcuq

Cite this article as: Monneret D. High-sensitive cardiac troponin after CPAP in obstructive sleep apnoea: the adjusted analytical change limit (adjACL) for small variations at low concentrations. Eur Respir J 2022; 59: 2103022 [DOI: 10.1183/13993003.03022-2021].
\end{abstract}




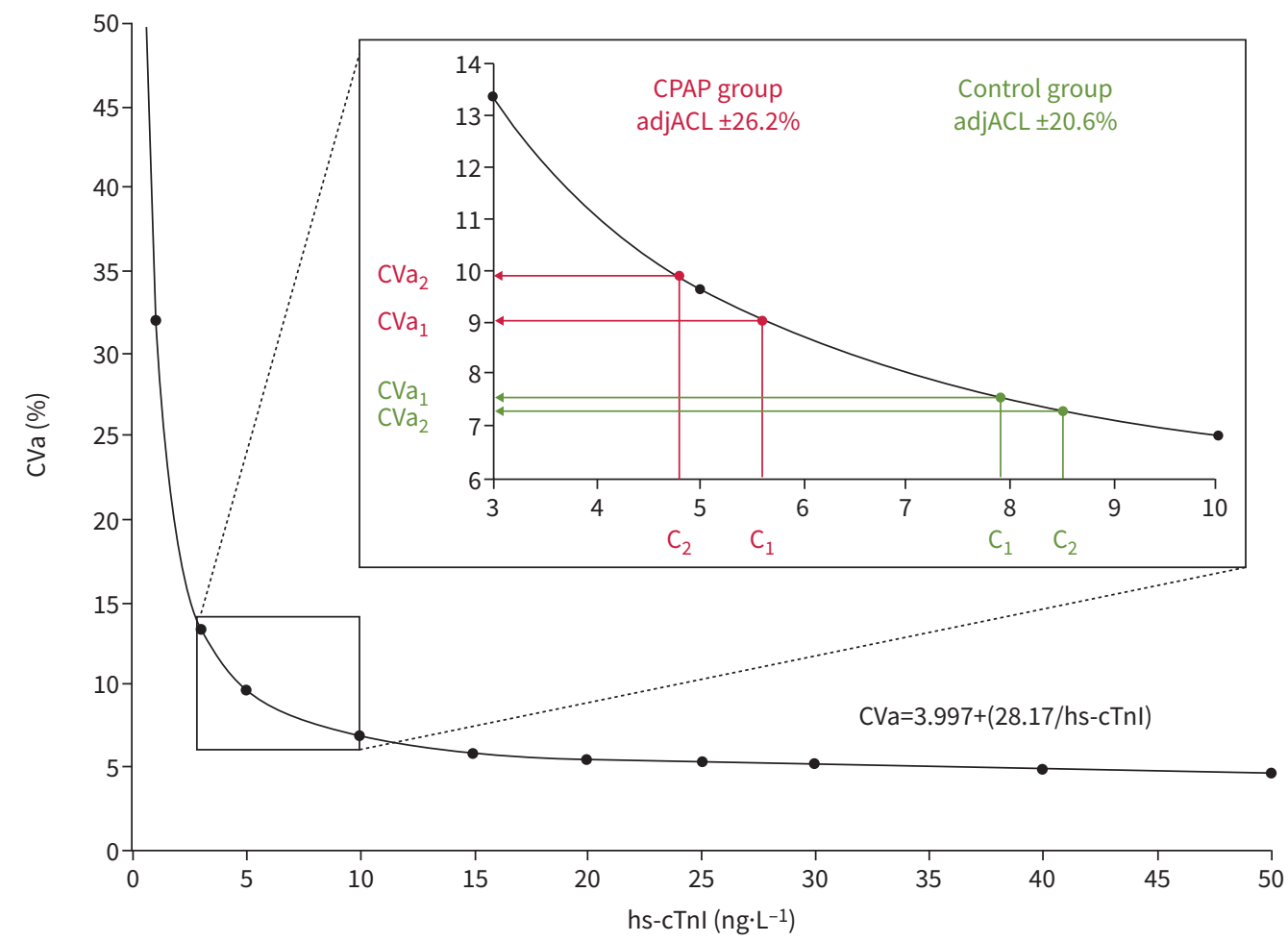

FIGURE 1 Mean imprecision profile of high-sensitive cardiac troponin I (hs-cTnl) determined on Architect analyser (Abbott, Chicago, IL, USA), using analytical coefficient of variation (CVa) and mean hs-cTnl concentrations provided in supplementary data from [2]. $\mathrm{CVa}_{1}$ and $\mathrm{CVa}_{2}$ are the analytical coefficients of variation corresponding to the hs-cTnl concentrations before $\left(C_{1}\right)$ and after $\left(C_{2}\right)$ an 8-week period with (red) or without (green) continuous positive airway pressure (CPAP) treatment, and calculated according to the equation of the nonlinear regression curve. The adjusted analytical change limits (adjACL) were calculated according to the formula $\pm 1.96 \times\left(\mathrm{CVa}_{1}{ }^{2}+\mathrm{CVa}_{2}{ }^{2}\right)^{1 / 2}[4]$.

Analytical imprecision of troponin is rarely considered in clinical studies, and even less when outcomes rely on serial results. Few studies have evaluated the effect of CPAP on hs-cTnT in OSA, but they overall concluded an absence of significant effect $[8,9]$. Lus et al. [3] were the first to focus on $\Delta$ hs-cTnI under CPAP, furthermore in a well-framed randomised controlled trial. They argued that hs-cTnT is "less sensitive than hs-cTnI in detecting subclinical myocardial injury", but this is not consensually acknowledged to date. hs-cTnI is more sensitive in the sense that a greater proportion of the general population has detectable concentrations (roughly 75\% versus 53\% for hs-cTnT), but it also has the drawback of being more strongly associated with age, male sex, body mass index and systolic blood pressure $(\mathrm{p}<0.0001$ for all versus hs-cTnT) [10], making these factors potentially more confounding. Cardiovascular co-morbidities are generally numerous in OSA, most of them impacting troponin levels. This is probably why most studies failed to show beneficial effects of CPAP on cardiovascular outcomes $[11,12]$. Further studies interpreting small changes in cardiac troponin at low concentrations under CPAP in OSA should consider the adjACL as an objective criterion, requiring a close collaboration between the clinic and the laboratory.

\section{Denis Monneret}

Service de Biochimie et Biologie Moléculaire, Laboratoire de Biologie Médicale Multi-Sites (LBMMS), Hospices Civils de Lyon (HCL), Lyon, France.

Corresponding author: Denis Monneret (dmonneret2@gmail.com) 
Conflict of interest: D. Monneret has nothing to disclose.

\section{References}

$1 \quad$ Willeit P, Welsh P, Evans JDW, et al. High-sensitivity cardiac troponin concentration and risk of first-ever cardiovascular outcomes in 154,052 participants. J Am Coll Cardiol 2017; 70: 558-568.

2 Clerico A, Padoan A, Zaninotto M, et al. Clinical relevance of biological variation of cardiac troponins. Clin Chem Lab Med 2020; 59: 641-652.

3 Lui MM-S, Tse H-F, Lam DC-L, et al. Continuous positive airway pressure improves blood pressure and serum cardiovascular biomarkers in obstructive sleep apnoea and hypertension. Eur Respir J 2021; 58: 2003687.

4 Monneret D, Gellerstedt M, Bonnefont-Rousselot D. Determination of age- and sex-specific 99th percentiles for high-sensitive troponin T from patients: an analytical imprecision- and partitioning-based approach. Clin Chem Lab Med 2018; 56: 685-696.

5 Collinson PO, Saenger AK, Apple FS, et al. High sensitivity, contemporary and point-of-care cardiac troponin assays: educational aids developed by the IFCC Committee on Clinical Application of Cardiac Bio-Markers. Clin Chem Lab Med 2019; 57: 623-632.

6 Wu AHB, Kavsak PA, Aakre KM, et al. Lot-to-lot variation for commercial high-sensitivity cardiac troponin: can we realistically report down to the assay's limit of detection? Clin Chem 2020; 66: 1146-1149.

7 Kavsak PA, Jaffe AS, Greene DN, et al. Total analytic error for low cardiac troponin concentrations ( $\leqslant 10 \mathrm{ng} / \mathrm{L})$ by use of a high-sensitivity cardiac troponin assay. Clin Chem 2017; 63: 1043-1045.

8 Chang YS, Yee BJ, Hoyos CM, et al. The effects of continuous positive airway pressure therapy on Troponin-T and $\mathrm{N}$-terminal pro B-type natriuretic peptide in patients with obstructive sleep apnoea: a randomised controlled trial. Sleep Med 2017; 39: 8-13.

9 Zhang XB, Zeng HQ, Du YP, et al. High-sensitivity cardiac troponin T in obstructive sleep apnea patients without cardiovascular diseases: efficacy of CPAP treatment. Chron Respir Dis 2018; 15: 157-164.

10 Welsh P, Preiss D, Shah ASV, et al. Comparison between high-sensitivity cardiac troponin T and cardiac troponin I in a large general population cohort. Clin Chem 2018; 64: 1607-1616.

11 McEvoy RD, Antic NA, Heeley E, et al. CPAP for prevention of cardiovascular events in obstructive sleep apnea. N Engl J Med 2016; 375: 919-931.

$12 \mathrm{Yu}$ J, Zhou Z, McEvoy RD, et al. Association of positive airway pressure with cardiovascular events and death in adults with sleep apnea: a systematic review and meta-analysis. JAMA 2017; 318: 156-166. 